\title{
La evolución de la adhesión a dentina
}

\author{
Camps Alemany I*
}

\section{RESUMEN}

Se realiza una revisión a la historia de la adhesión comenzando en las culturas precolombinas ("era pre-adhesiva"), para continuar en la "era adhesiva" con las aportaciones de Buonocuore y la aparición del Bis-GMA, pasando por la incorporación al mercado dental de los fosfatos, los oxalatos, el sistema Gluma. Se analiza también la descripción la capa híbrida por Nakabayashi, después aparecen los primers acuosos y la hibridación de tejidos duros hasta llegar a los sistemas adhesivos autograbadores.

Palabras clave: Historia, adhesion, dentina.

\section{ABSTRACT}

An overview of dentin bonding history is done by the author since early south American cultures (pre-adhesive age) to continued in the adhesive age with Buonoccore's findings and the rise of Bis-GMA and the first dentin adhesives based on phosphate, oxalate and Gluma system. Nakabayashi's hybrid layer is described and the evolution of aqueous primers and hard tissues hybridation until arrival of newest self-etching adhesives.

Key words: History, dentin, bonding.

Aceptada para publicación: octubre 2003

* Prof. Asociada. Facultad de Odontología. Valencia.

Camps Alemany I. La evolución de la adhesión a dentina. Av. Odontoestomatol 2004; 20-1: 11-17.

\section{ERA PRE-ADHESIVA}

El tratamiento restaurador de los diente, en la actualidad se lleva a cabo, gracias a la interacción entre el material restaurador y la estructura dentaria, mediante el uso de un sistema adhesivo, lo que permite que tanto mecánica como biológica, como funcionalmente el diente y su material restaurador funcionen como una unidad. No obstante, esta unidad desde el punto de vista adhesivo, responde a una serie de técnicas y materiales que se han ido desarrollando, de forma muy diferente, a lo largo del devenir de la Historia de la Odontología.

Uno de los primeros hallazgos odontológicos de los que se tiene conocimiento, se sitúa en las culturas precolombinas de incas y mayas, entre el 300 y el 900 d.C., los cuales realizaban incrustaciones de pie- dras preciosas en incisivos superiores e inferiores, e incluso en primeros molares, siendo los principales minerales utilizados para tales fines la jadeíta, pirita, hematites, turquesa, cuarzo, serpentina, cinabrio,.. etc. que colocaban sobre dientes vivos, a los que previamente se les había perforado, mediante el uso de un taladro de cuerda que atravesaba el esmalte y llegaba a la dentina creando una cavidad, que era ocupada con mucha exactitud por la piedra, apreciándose en los hallazgos arqueológicos, la presencia de cementos a base de fosfato cálcico, no se sabe si utilizado para sellar o si formaba parte del abrasivo para taladrar.

Sociedades tribales primitivas, en la actualidad, situadas en áreas remotas de Malasia, también practican tipos de ornamentación similares, incrustando en sus dientes trozos de alambre de latón y piedras semipreciosas. 
Tanto en unas como en otras sociedades primitivas, las incrustaciones respondían, más que a cánones estéticos o terapéuticos, a rituales de tipo religioso o cultural.

Otra forma de reponer y sujetar los dientes perdidos o artificiales junto a los dientes naturales situados en la arcada dentaria, viene descrita en los textos obtenidos de los etruscos, que unían unos dientes a otros mediante tiras de oro. (Musée de l'École Dentaire. Paris). Lo que también era una práctica frecuente entre los egipcios y fenicios.

En el mundo Islámico, Razés que recopila en su libro "Kitah al Hawi" los conocimientos odontológicos árabes desde el siglo VII al siglo X, aconseja la realización de empastes sobre los dientes careados, con una mezcla de alumbre y alfóncigo.

En la China, se desarrolla, en el II S d.C. una aleación de plata ("pasta de plata") que sería utilizada hasta varios siglos después, ya que se menciona en textos de Su Kung (659 d.C.), en el periodo Ming y en las "Materias Médicas"de Liu Wen-t'ai en 1505. Dicha pasta de plata se componía de 100 partes de mercurio, por 45 partes de plata y 900 de Zinc.

Marco Polo cuenta (1270) como los hombres y mujeres chinos, tenían por costumbre, cubrir los dientes con trozos de oro, perfectamente ajustados, para que quedasen adheridos.

La Edad Media hace uso del oro como material de elección en los tratamientos dentales, tal y como lo describe Arcolani (1422-1427) con el uso del pan de

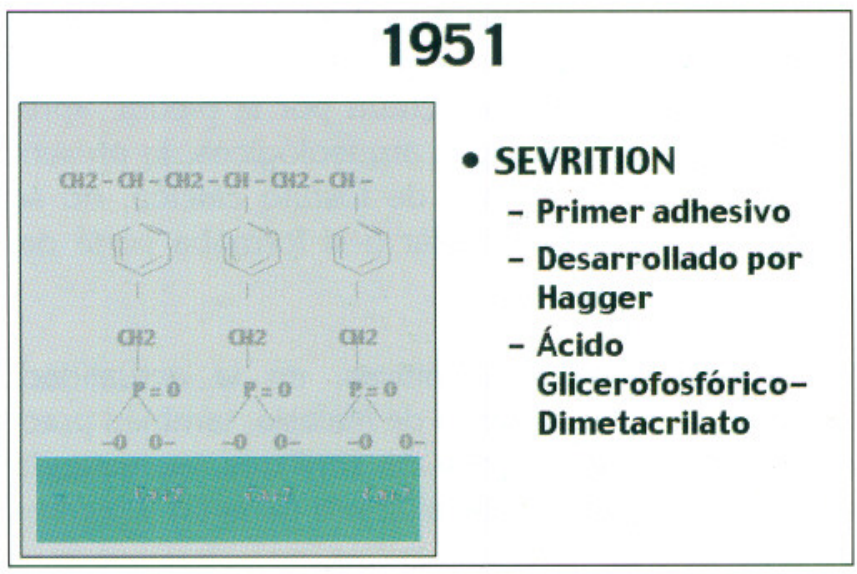

oro y Giovanni da Vigo (1460-1525) rellenando las cavidades con láminas de oro.

Durante el S XVIII, Pierre Fauchard (1726) describe en su obra "Le chirurgien dentiste ou le traité des dents"el relleno de los dientes con plomo y zinc. Al mismo tiempo Baker en América hacía empastes de oro y plomo. Años después Crawcour (1833) obtura dientes con virutas de plata de las monedas y mercurio.

A fines del S XVIII (1895), Black anuncia su fórmula de la amalgama de plata con pequeñas proporciones de estaño, cobre y zinc. Arthur introduce en 1855 las láminas de oro de gran adherencia y en 1879 aparece el cemento precursor del fosfato de zinc.

A principios del siglo XIX se empiezan a sellar los dientes con cemento de fosfato de zinc, siendo repuesto periódicamente por su incapacidad de adherirse al diente, lo que nos indica, que por lo menos hasta fines del S XIX, la odontología restauradora, se desarrollaba a expensas de nuevos materiales para cubrir las cavidades de los dientes careados pero no se había conseguido realizar una interacción entre éstos y la estructura dental. Es a partir de que esta interrelación entre el diente y el material restaurador cuando se podría hablar del comienzo de la "Era adhesiva" en la Odontología.

\section{ERA ADHESIVA}

Para que la adhesión al diente se produjera eficazmente, se debía partir de un conocimiento exhaustivo de la estructura del esmalte y la dentina. De éstos se sabía que la dentina presentaba un comportamiento diferente al del esmalte, siendo la primera mucho más hidrófila y compuesta por un $70 \%$ de

\section{6}

\section{- Resina de BOWEN (BIS-GMA) Bisfenol Glicidil Metacrilato}

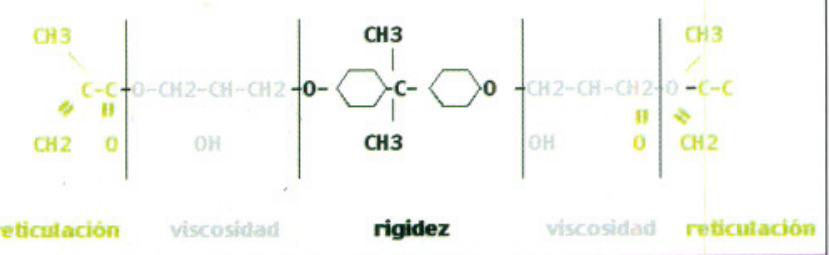


hidroxiapatita, un $18 \%$ de colágeno y un $12 \%$ de agua, frente al esmalte bastante menos hidrófilo, y constituido por un $95 \%$ de material inorgánico, un $4 \%$ de agua y un $1 \%$ de material inorgánico.

Hacia la década de los cincuenta, tenía lugar la aparición en la Odontología adhesiva, del primer adhesivo SEVRITION (1951), desarrollado por Hagger y cuya composición era la del ácido glicerofosfóricodimetacrilato. En un medio húmedo, la unión era inestable y se descomponía.

El comienzo real de la Odontología Adhesiva, tuvo lugar en 1955 con Michael Buonocore que fue el primero en describir el efecto sobre el esmalte de la aplicación de una solución ácida, que después se lavaba y secaba y con la que se obtenía un patrón de grabado con ácido de la superficie adamantina. El ácido actúa disolviendo selectivamente los extremos finales de los prismas de esmalte en la superficie, lo que consigue una superficie porosa e irregular, capaz de ser mojada y penetrada por una resina fluida, de baja viscosidad, que moja la superficie de los poros e irregularidades creadas por la disolución de los prismas de esmalte.

Al hallazgo de Buonocore, se sumó Bowen con la obtención de una resina capaz de adherirse al diente grabado con ácido. Dicha "resina de Bowen" es el bisfenol-glicidil-metacrilato (Bis-GMA).cuya formulación contempla dentro de la molécula la presencia de tres zonas, una central que le confiere la rigidez a la resina, dos áreas a lo largo de la cadena, que le proporcionan la viscosidad y unos extremos que le permiten establecer una reacción de polimerización, para conseguir la reticulación de dicho polímero.

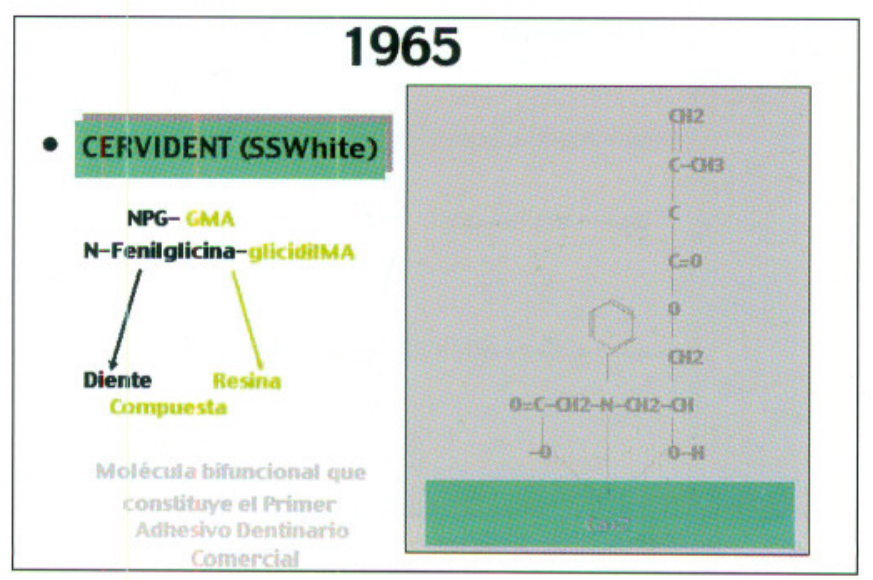

En 1965, Bowen propone el primer adhesivo dentinario comercial, con una molécula, el NPG-GMA ( $\mathrm{N}$ fenilglicina-glicidil Metacrilato) que tenía carácter bifuncional, de forma que el extremo del metacrilato se uniría a la resina compuesta como material restaurador y el otro extremo se uniría a la dentina. Este adhesivo se comercializó como Cervident de la S:S: White. Los resultados clínicos a los 3 años mostraban un considerable $50 \%$ de fallos y más de la mitad de éstos tenía lugar en los primeros 6 meses de tratamiento. Las causa se atribuyen a las pobres propiedades de humectancia, cristalizando postsecado, lo que reduce la superficie disponible para la unión con la resina compuesta.

En 1978, se comercializa el primer adhesivo dentinario a base de fosfatos, Clearfil Bond System de Kuraray, que contenía un monómero hidrófobo, el metacriloxietil-fenil-hidrógenofosfato, junto con un metacrilato hidrosoluble, HEMA (Hidroxietilmetacrilato) e incorporando activadores químicos, por lo que se presento como un sistema de dos componentes, es lo que los promotores de la reacción de polimerización se repartían entre ambos componentes. Su mecanismo de unión se basaba en la interacción entre los fosfatos y el calcio de la dentina y del esmalte sin grabar. La capacidad de adhesión era todavía muy pobre debido a la poca capacidad de humectar la dentina, y se situaba alrededor de los $3 \mathrm{Mpa}$, valores que mejoraron cuando fue utilizado junto a una técnica de grabado ácido del esmalte, también el de la dentina (grabado total).

En la década de los 80 tiene lugar una explosión de adhesivos dentinarios de diferentes composiciones químicas:

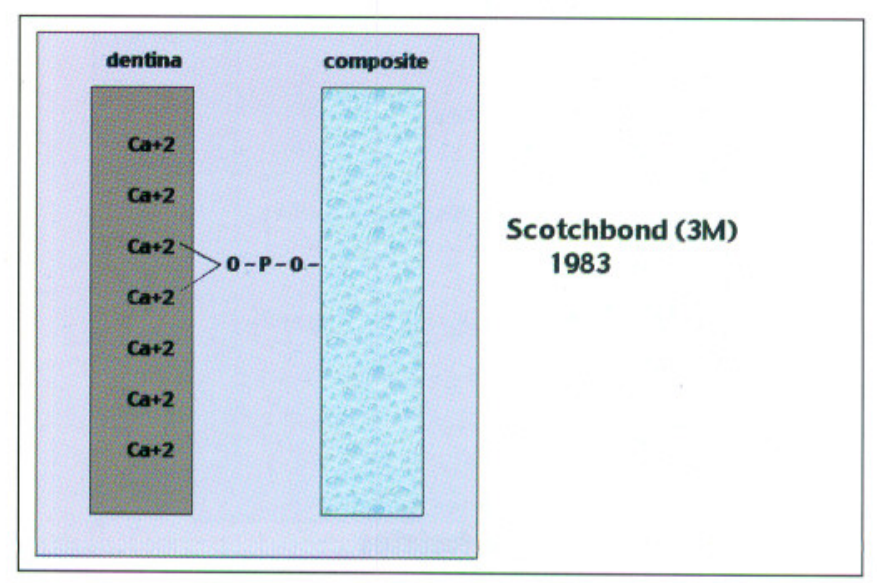




\section{Los fosfatos}

La capacidad de unión se establece por la reacción entre el fosfato del adhesivo y el calcio de la estructura dental. Bajo este concepto químico, se comercializa en 1983 el Scotchbond (3M), un esterfosfato del Bis-GMA que se presentaba en dos componentes: la resina hidrofóbica formada por Diclorofosfato de BisGMA al 57\%, un 43\% de TEG-DMA (Trietilglicidildimetacrilato) y pequeñas cantidades del iniciador de peróxido de benzoilo y el otro componente, el líquido, constituido por un $98 \%$ de etanol, aceleradores (canforoquinonas al $0,06 \%$ en los fotopolimerizables y sulfocinato sódico de benceno, para los foto y autopolimerizables. La capacidad de unión al esmalte casi se había duplicado, en relación al adhesivo dentinario de la década anterior, hasta los 5 Mpa, pero la adhesión a dentina sólo conseguía una séptima parte que la del esmalte. En su mecanismo de acción, también se debía considerar el efecto reblandecedor del smear layer. Se pensaba que los grupos fosfatos podían crear una unión química a la dentina, gracias al calcio del barrillo dentinario.

El optimismo que generó la molécula de fosfato del Scotchbond, hizo proliferar durante la década de los 80 , de diferentes adhesivos a base de fosfatos. . Son nombres comerciales pertenecientes a este grupo: Bondlite (Kerr), Universal Bond (Caulk)Dentin Bonding agent (JEJ), Synter Bond (Teledyne Getz), creation Bond (Dent Mat).

La aparición rápida de diversos sistemas a base de

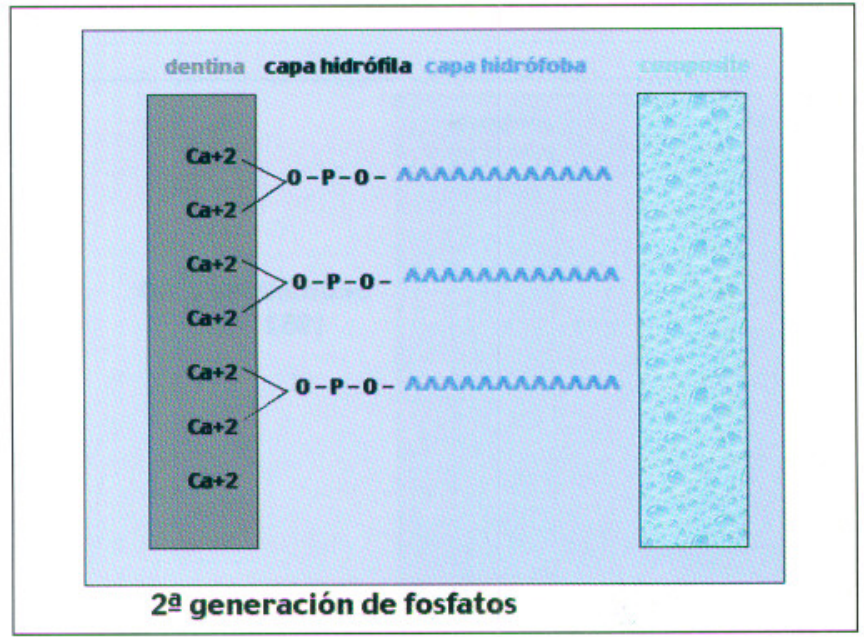

fosfatos sin que diera tiempo a probar su eficacia, condicionó la introducción de nuevos adhesivos sin probar, escapándose de los tests previos, apoyándose en el artículo 512 sobre "Drogas y Alimentos", donde lo que requiere es probar su eficacia. El fracaso acontecía por disociación del fosfato, separación del SL y pérdida de la unión a dentina, presentando como consecuencia la microfiltración entre el composite y el diente. La diferencia en los coeficientes de expansión térmica producía filtraciones y aceleraba el proceso. La longevidad era impredecible pese a ser exitosa inicialmente, de modo que sin grabado ácido el $30 \%$ de las obturaciones cervicales fallaba y con el grabado se caen al año, alrededor del $10 \%$.

Entre 1984 y 1989, se comercializa el Clearfil New Bond y el Clearfil Fotobond de Kuraray, que era un nuevo fosfato que contenía un grupo hidrofóbico largo (MDP -Metacriloxyetildihidrógeno fosfato-) y un grupo hidrofílico con mayor humectancia (HEMA). Los resultados clínicos no eran mejores si no se grababa la dentina con ác. Fosfórico.

\section{Los oxalatos}

Desde 1965, pero principalmente desarrollados en esta década de los ochenta. Bowen y Cobb trabajaron con e introdujeron los sistemas de oxalatos. Estos autores describen un sistema de unión con una solución acuosa de oxalato férrico, que luego lo sustituyeron por el oxalato de aluminio para evitar la tinción del diente.

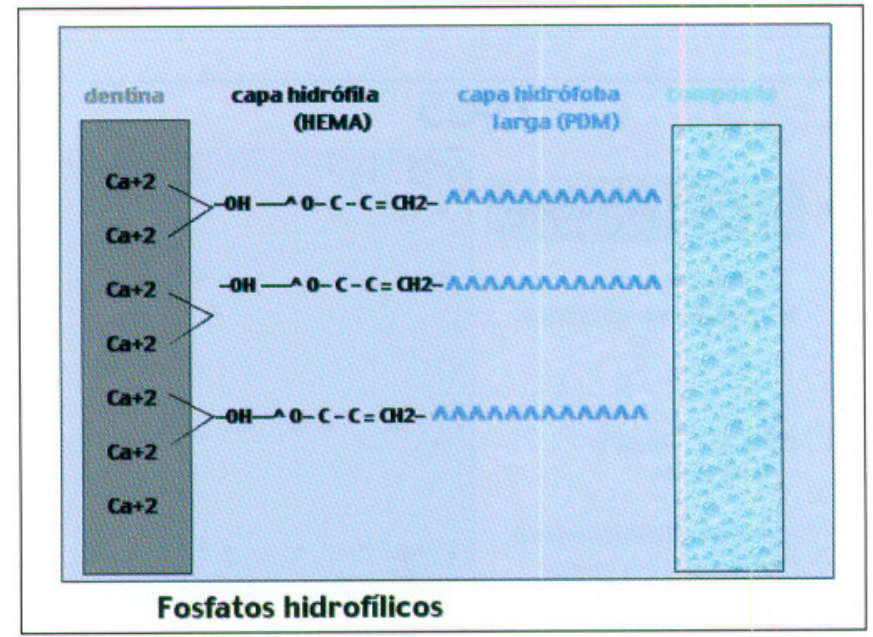


El primer producto comercial fue el Tenure introducido por la casa Den-Mat en 1982, que era un sistema muy complejo de 8 pasos que luego se simplificó y se presentaba como un acondicionador que contenía oxalato de aluminio al 3,5\%, ác. Nítrico al $2,5 \%$ y un $94 \%$ de agua, una solución A con NPGGMA en acetona al $94 \%$ y una solución $B$ que era un $10 \%$ de PM-DM. Su mecanismo de acción parece que despegaba el smear layer para que la reina pudiera fluir por los túbulos dentinarios. Su comportamiento clínico era variable, según el tipo de estudio que se realizase.

Los adhesivos dentinarios a base de fosfatos y oxalatos suponen lo que algunos autores conocen como adhesivos de $1^{\mathrm{a}}$ y $2^{\mathrm{a}}$ generación.

\section{El sistema Gluma}

En 1985, Munksgaard y Asmussen promueven un adhesivo dentinario que graba el esmalte con ácido fosfórico al 37\%. Graba la dentina con EDTA al $17 \%$. Posteriormente se imprima la superficie del diente con glutaraldehido al $5 \%$ que reacciona con la dentina. Se produce después, una reacción de condensación con el HEMA al 35\% y un $65 \%$ de agua junto con el glutaraldehido. El siguiente paso es colocar una resina fluida a la que se aplica la luz de polimerización.

El mecanismo de acción del Gluma, es el de su unión con el colágeno de la dentina. El Gluma fue el adhesivo dentinario más vendido de 1985.Posee una corta vida de almacenamiento. Forma polímeros con el glutaraldehido que suponen una barreara a la penetración del monómero en las fibras de colágeno. En 1987 fue comercializado el producto en EEUU.

El sistema Gluma junto a adhesivos dentinarios como el Mirage Bond (Myros), Restbond (Lee), son algunos de los adhesivos considerados de la tercera generación.

\section{La capa híbrida}

El camino hacia la cuarta generación de adhesivos dentinarios, también fue acompañado en el devenir histórico de estudios en el diente que revolucionaron la adhesión dentinaria.

El paso más importante que ha dado la adhesión dentinaria y que ha marcado la operatoria, ha sido el descubrimiento por Nakabayashi en 1982 de la "Capa Híbrida"concepto que justifica la imbricación de la resina del adhesivo entre la dentina, de forma que al resina se sitúa entre las redes de colágeno, imbricándose entre ellas y a su vez es capaz de introducirse en los túbulos dentinarios parcialmente desmineralizados, para crear auténticos tags entre los mismos. La imbricación de los tejidos duros del diente una vez tratados con ácido, con la resina crea la imagen histológica de la "Capa Híbrida".

Para conseguir la hibridación, los pasos que recomienda Nakabayasahi son el grabado de la dentina con una solución del 10:3 de ácido cítrico al 10\%, que elimina el smear layer y graba la hidroxiapatita (entre 5-10 micras), junto con el grabado con cloruro férrico al $3 \%$ que crea la desnaturalización y coagulación de los haces de colágeno. A continuación del grabado, se debe proceder a la imprimación con un monómero hidrófilo capaz de infiltrarse en la dentina e incorporar en los haces de colágeno.

\section{Los primers acuosos}

En la década de los 90, con la intención de utilizar adhesivos dentinarios más hidrofilicos, por seguir las características de la dentina, y así mejorar la capacidad de unión, aparecen los adhesivos dentinarios basados en primers acuosos. Estos constan de un acondicionador de dentina y esmalte (EDTA, Ác. Nítrico, poliexidina,...) que limpia la interfase dental y usualmente retiran el barrillo dentinario. Casi siempre son lavados después de aplicar el acondicionador. También constan del "Primer Acuoso" propiamente dicho, que humedece la superficie de la dentina, incrementa la permeabilidad del barrillo dentinario, proveen retención micromecánica de la superficie dentinaria y provee de unión química, lo que mejora el potencial de interacción química entre el barrillo alterado y la superficie de la dentina. El adhesivo, como resina hidrofóbica sería el tercer elemento.

Adhesivos dentinarios que utilicen este sistema de 
"Primers Acuosos"son: Scotchbond 2, XR Bond (Kerr), Primer Universal Bond 2 y Tripton (coE). La capacidad de unión de éstos, estaba alrededor de los 10-12 Mpa. Estos adhesivos pertenecerían a la $4^{\mathrm{a}}$ generación.

\section{Hibridación de tejidos duros}

La creación de una capa híbrida con el tejido dentario es conseguida por adhesivos dentinarios del tipo de "All Bond 2" que graba con ác. Fosfórico, esmalte y dentina, imprima con el BPDM (Bifenildimetacrilato) y acetona, utilizando como resina la NTGGMA (N-Toliglicina-glicidil-metacrilato). El Scotchbond Multipurpose y Multipurpose Plus, realizan el grabado con ác. Maleico o con ác. Fosfórico para luego imprimar y colocar la resina. Syntac y Denthesive II acondicionan por separado el esmalte de la dentina.

\section{Adhesión dentinaria en la actualidad}

La capacidad de unión a las estructuras dentales en la actualidad, es clínicamente aceptable y los sistemas adhesivos se han desarrollado para lograr la simplificación de la técnica con el objeto de minimizar errores y evitar pasos clínicos que los originen, lo que ha dado pie a huir de las clasificaciones basadas en los cambios igeneracionales y fundamentar la clasificación según su forma de uso. Así podemos hablar de adhesivos dentinarios de un de dos o tres pasos clínicos. En este último caso, el primer paso sería el acondicionamiento o grabado del diente, el segundo la imprimación con la resina hidrófila y el tercero la impregnación con la resina adhesiva. Estos dos últimos pasos, pueden simplificarse en uno solo, de forma que tras el grabado, impregnaríamos la superficie del diente lavada y secada postgrabado, con luna solución que lleva resinas hidrófilas e hidrófobas.

Van Meerbeek describe en la actualidad, tres grandes grupos de materiales para conseguir la adhesión al diente. De un lado, aquellos adhesivos dentinarios que realizan un grabado total del esmalte y la dentina; otros tipo de adhesivos son los que se denominan adhesivos autograbantes, de modo que consiguen el acondicionado o grabado, junto con la impri- mación y en tercer lugar los ionómeros de vidrio que poseen capacidad adhesiva.

Los adhesivos dentinarios con grabado total realizan su función en tres pasos:

- ácido para grabar

- primer

- resina

o en dos pasos: ácido para grabar

- imprimación y aplicación de la resina.

La otra vía para conseguir una adhesión dentinaria eficaz, sería mediante el uso de adhesivos autograbantes, que supone el uso de monómeros ácidos que no se lavan y acondicionan e imprimen la dentina y el esmalte. Se suelen presenta en dos frascos.

La capacidad de grabado de estos materiales, hacen que se puedan clasificar en adhesivos autograbantes suaves y autograbantes fuertes

Los ionómeros de vidrio que presentan una composición química bien diferente a los anteriores adhesivos,, ya que se unen al diente por un proceso de quelación con el calcio, son cementos que son capaces de unirse al diente y al composite, liberan fluor, poseen una capacidad de unión parecida a la de los adhesivos autograbantes suaves, altamente compatibles con las estructuras vivas y con materiales entre si. Se encuentran en las últimas décadas en constante desarrollo en relación a poseer características propias de los composites.

\section{BIBLIOGRAFÍA}

ALBERS H.F (1988): Odontología Estética. Selección y colocación de materiales. Ed. Labor.

ALBERS H.F. (1996) tooth-colored restoratives. An introductory Text for selecting placing and finishing direct systems.

BOWEN R.L: Dental Filling Material Comprising vinyl silane treated fused silica and a binder consisting of a reaction product of bisphenol and glycidyl acrylate. U.S. Patent. Nov. 1962. 
BOWEN R.L.: Use of epoxy resins to restorative materials" J. Dent.Res; 35 (3): 360-9.

BUONOCORE: ."A simple metod of increasing the adhesión of acrylic filling materials to enamel surfaces"J.Dent.Res: 34: 849-53.

CRISPIN B.J : (1998) Adhesión de resina a la estructura dentaria. En Bases prácticas de la Odontología Estética. Masson.

DEGRANGE M, ROULET J.F.: (1997) Minimally Invasive restorations with bonding. Quintessence books.

GORACCI et al : (1994) otturazioni in composito ed adesione alle strutture dentaire. Ed Masson.

GUZMAN BAEZ H.J: (1990)Polímeros. En Biomateriales Odontológicos de uso clínico"CAT Editores.

MALVIN E RING. Historia de la Odontología. Ed. Doyma.

SCHMIDSEDER J.: (1999) Historia de loa adhesivos dentinarios en Atlas de Odontología Estética.
VANHERLE G, DEGRANGE M, WILLEMS G (1993): State of the art on direct posterior filling materials and dentine bonding.

VAN MEERBECK et al.: (2001) Adhesives and Cements to promote preservation dentistry. Oper. Dent. Suppl. 6,2001, 119-44.

VEGA DEL BARRIO J.M. (1996): Sistemas adhesivos en Materiales en odontología. Fundamentos biológicos, clínicos, biofísicos y físico-químicos. Ed. Avances.

WILSON N, ROULET J.F, FUZZI M: (2001) advances in Operative Dentistry.

\section{CORRESPONDENCIA}

Facultad de Medicina y Odontología

Universidad de Valencia

Avda. Blasco Ibáñez, 15-17

46010 Valencia 
